\title{
Obtenção e caracterização de membranas cerâmicas tubulares a partir de massas incorporadas com argila, caulim e quartzo
}

\section{(Preparation and characterization of tubular ceramic membranes using mass incorporated with clay, kaolin and quartz)}

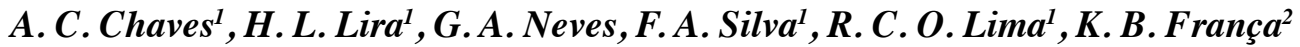 \\ ${ }^{I}$ Departamento de Engenharia de Materiais, ${ }^{2}$ Laboratório de Referência em Dessalinização (LABDES), \\ Universidade Federal de Campina Grande, Av. Aprígio Veloso, 882, Campina Grande, PB 58109-970 \\ alexsandra@dema.ufcg.edu.balexsandrachaves@hotmail.com;helio@dema.ufcg.edu.br; gelmires@dema.ufcg. \\ edu.br;falmeidasilva@gmail.com; rosacolima@yahoo.com.br; kepler@labdes.ufcg.edu.br
}

Resumo

\begin{abstract}
A tecnologia que envolve a utilização de membranas cerâmicas tem nas ultimas décadas se transformado numa importante técnica de separação. Os principais motivos no avanço dessa tecnologia estão relacionados ao fato de que trabalham sem a adição de agentes químicos, baixo consumo de energia, facilidade de processamento e arranjos físicos compactos. Hoje a principal preocupação no desenvolvimento dessas membranas é minimização dos custos e a obtenção de processos de produção mais eficientes. Diante disto, a utilização de matérias-primas naturais vem como uma alternativa para obtenção de membranas cerâmicas, utilizando como método de produção a extrusão. Visando contribuir com a pesquisa tecnológica, o presente trabalho teve como objetivo a utilização de matérias-primas naturais, tais como argila, quartzo e caulim na confecção em escala laboratorial de membranas cerâmicas tubulares utilizando como processo de produção a extrusão. A massa cerâmica foi submetida às caracterizações: física e mineralógica através de ensaios de análise granulométrica, termogravimétrica, difração de raios $\mathrm{X}$ e análise química por fluorescência de raios X. As amostras foram sinterizadas a $800,900,1000$ e $1100{ }^{\circ} \mathrm{C}$ com o objetivo de verificar a influência nas características das membranas. As membranas cerâmicas obtidas foram caracterizadas por microscopia eletrônica de varredura e porosimetria por intrusão de mercúrio, sendo possível verificar a ausência de defeitos e trincas em sua estrutura. Com relação à análise de porosimetria, foram observados poros na faixa de ultrafiltração.
\end{abstract}

Palavras-chave: membranas cerâmicas, ultrafiltração, caracterização.

Abstract

The technology that involves the use of ceramic membranes has become in the last decades an important separation technique. The main reasons in the advance of this technology are related to the fact that work without addition of chemical reagents, low consumption of energy, ease to processing and compact physical arrangements. Today the main concern in the development of these membranes is to minimize the costs and more efficient production processing. In this way the use of natural raw materials comes as an alternative to prepare ceramic membrane, using extrusion as processing technique. The aim of this work is to study the use of natural raw materials, such as, clay, quartz and kaolin to prepare tubular ceramic membranes in laboratorial scale using extrusion processing. The ceramic mass was submitted to characterizations: physical and mineralogical through particle size, thermogravimetry, X-ray diffraction and X-ray fluorescence analysis. The samples were sintered at temperatures of 800, 900,1000 and $1100^{\circ} \mathrm{C}$, with the aim to verify the influence on membrane characteristics. Ceramic membranes were characterized by scanning electron microscopy and mercury porosimetry, were it was possible to verify the absence of defects and cracks in its structure. In relation to the porosimetry analysis, pores in the range of ultra-filtration were observed.

Keywords: ceramic membranes; ultrafiltration; characterization.

\section{INTRODUÇÃO}

As membranas cerâmicas porosas que são comercializadas atualmente são feitas principalmente com alumina, zircônia, titânia, sílica, e não são adequadas para aplicações em grande escala, especialmente em processos de separação que não envolve produtos de alto valor agregado. Isto devido às matérias-primas caras e queima em temperaturas relativamente altas [1]. A fabricação de membranas inorgânicas tendo como componentes principais minerais naturais, como argilas, tem recebido pouca atenção na literatura $[1,2]$. Os minerais são considerados industriais, quando são empregados na atividade humana por suas propriedades físicas, químicas ou ornamentais. Entretanto, deixam de ser considerados como tais, se o seu consumo for direcionado para a metalurgia e geração de energia [3]. Os minerais industriais à medida que recebem maior valor agregado, ou seja, são transformados com a utilização de 
técnicas específicas, podem se tornar mais competitivos, pois possibilitam um maior alcance de mercado, já que, atualmente, as indústrias exigem cada vez mais qualidade e especificações que nem todas as rochas e minerais possuem, determinando assim, estudos e desenvolvimento tecnológico sobre os mesmos. A região nordeste do Brasil é bastante rica em recursos minerais para desenvolvimento de produtos cerâmicos. Dentre estes, os mais importantes são: argila, caulim, quartzo, feldspato, etc. Autores vêm desenvolvendo trabalhos, onde mostra a utilização dessas matériasprimas na indústria cerâmica $[4,5]$. A utilização desses argilominerais como matéria-prima e sua transformação em produtos que possam ser comercializados ou que se mostrem economicamente viáveis, se apresenta como uma opção interessante para as indústrias. Estes minérios possuem potencial de aplicação na obtenção de membranas cerâmicas, podendo ser submetidos ou não a um beneficiamento visando alterar suas características físicas. A utilização de membranas cerâmicas tem aumentado nas ultimas décadas e vem se transformado numa importante técnica de separação. Os principais motivos no avanço dessa tecnologia na separação dos diversos tipos de materiais estão relacionados ao fato de que trabalham sem a adição de agentes químicos, com baixo consumo de energia, facilidade de processamento e arranjos físicos compactos [6]. As membranas em geral são amplamente empregadas em diferentes processos de separação, tais como, tratamento de rejeitos industriais, processamento de alimentos, dessalinização de águas, processos biomédicos, têxteis e químicos [7, 8].

O emprego das tradicionais membranas poliméricas é limitado a temperaturas inferiores a $250{ }^{\circ} \mathrm{C}$ e sofrem degradação acelerada em pH extremamente ácido ou na presença de solventes orgânicos [9]. O grande avanço tecnológico alcançado na área de membranas cerâmicas está relacionado à possibilidade de obtenção de membranas com considerável diminuição dos tamanhos dos poros, tornando viável sua utilização em processos de microfiltração, ultrafiltração [10], e em nanofiltração [11]. Foram desenvolvidos estudos com membranas cerâmicas a partir de argilominerais, com êxito, mostrando que esses matériais podem ser uma forma alternativa e econômica no desenvolvimento dessa tecnologia [12]. Visando contribuir com a pesquisa tecnológica, este trabalho teve como objetivo a utilização de matérias-primas naturais, tais como argila, quartzo e caulim na confecção em escala laboratorial de membranas cerâmicas tubulares utilizando como processo de produção a extrusão.

\section{EXPERIMENTAL}

As matérias-primas utilizadas para confecção das membranas estão listadas na Tabela I. Inicialmente foi feita a homogeneização da massa cerâmica em um misturador planetário, com a composição predefinida na Tabela I, onde se adicionou $20 \%$ água e $3 \%$ de óleo diesel, com o intuito de se obter uma massa homogênea e com plasticidade adequada para ser conformada pelo processo de extrusão.
Tabela I - Matérias-primas utilizadas.

[Table I - Raw materials used.]

\begin{tabular}{cc}
\hline Matérias- Primas/Origem & Composição (\%) \\
\hline Bentonita-Cubatí (PB) & 48 \\
Caulim-Assunção (PB) & 22 \\
Quartzo-Parelhas (PB) & 30 \\
\hline
\end{tabular}

\section{Ensaios de caracterização da massa cerâmica}

Após completa homogeneização da massa cerâmica, foi feita caracterização física e mineralógica com ensaios de análise granulométrica por difração a laser, análise química, análise termogravimétrica e difração de raios $\mathrm{X}$, com a finalidade de determinar o seu estado de cominuição, componentes químicos e fases mineralógicas.

Análise granulométrica por difração a laser $(A G)$ : neste método é combinada à relação proporcional entre a difração a laser, a concentração e o tamanho de partículas. A massa cerâmica verde foi passada em peneira ABNT 200 $(0,074 \mathrm{~mm})$, e dispersas em $250 \mathrm{~mL}$ de água destilada em agitador Hamilton Beach N-5000 a 17.000 rpm por 20 min; em seguida, $15 \mathrm{~mL}$ são separados e colocados em dispersor ultrassônico por $10 \mathrm{~min}$; depois, esta dispersão é colocada em um equipamento CILAS 1064, em modo úmido, até atingir a concentração ideal, que é de 150 unidades de difração/área de incidência.

Análise química por fluorescência de raios $X(E D X)$ : as matérias-primas e a massa cerâmica verde foram passadas em peneira ABNT 200 e submetidas à análise química por fluorescência de raios X no equipamento EDX Shimadzu 720.

Analise termogravimétrica (TG): a análise termogravimétrica da massa cerâmica foi feita em equipamento BP Engenharia RB 3000 operando a $10{ }^{\circ} \mathrm{C} / \mathrm{min}$. A temperatura máxima utilizada na análise térmica foi $1000^{\circ} \mathrm{C}$.

Difração de raios $X(D R X)$ : a análise de DRX da massa cerâmica verde foi em equipamento XRD 6000 Shimadzu com radiação Cuka $(40 \mathrm{kV} / 30 \mathrm{~mA})$; a velocidade do goniômetro foi de $2^{\circ}$ /min e passo de $0,02^{\circ}$. A interpretação foi feita como os padrões contidos no programa computacional PDF 02 (ICDD, 2003).

Conformação das membranas cerâmicas: as membranas em formato tubular foram obtidas por extrusão, em uma extrusora a vácuo Verdéso 051. O molde utilizado foi confeccionado em aço VC 131, temperado, o qual permitiu que as peças extrudadas adquirissem a forma tubular com as seguintes dimensões: diâmetro externo $10,5 \mathrm{~mm}$, diâmetro interno 7,5 mm e parede do tubo de $\sim 1,5 \mathrm{~mm}$. As peças foram submetidas a duas etapas de secagem. Na primeira, secagem natural, durante 5 dias. Na segunda, as peças foram tratadas em estufa a $\sim 100{ }^{\circ} \mathrm{C} / 48 \mathrm{~h}$. Passada essa etapa, as peças cerâmicas foram cortadas com comprimento de $\sim 80 \mathrm{~mm}$. As temperaturas de queima foram $800,900,1000 \mathrm{e} 1100^{\circ} \mathrm{C} / 2 \mathrm{~h}$. As sinterizações foram em forno elétrico Maitec. A queima 
foi feita baseando-se na curva da análise termogravimétrica da massa cerâmica. As taxas de aquecimento foram $2{ }^{\circ} \mathrm{C} /$ min da temperatura ambiente até $400{ }^{\circ} \mathrm{C}, 1^{\circ} \mathrm{C} / \mathrm{min}$ de $400^{\circ} \mathrm{C}$ até $700{ }^{\circ} \mathrm{C}$ e $3{ }^{\circ} \mathrm{C} / \mathrm{min}$ de $700{ }^{\circ} \mathrm{C}$ até atingir as temperaturas máximas.

Caracterização das membranas cerâmicas: as membranas cerâmicas foram caracterizadas por ensaios de microscopia eletrônica de varredura e por porosimetria de intrusão de mercúrio. Através da análise de microscopia eletrônica de varredura foi possível avaliar a distribuição e prever os tamanhos de poros das membranas cerâmicas. $\mathrm{O}$ equipamento utilizado foi um microscópio eletrônico de varredura Shimadzu SuperScan SS500. Para o ensaio de porosimetria de mercúrio das membranas sinterizadas utilizou-se um porosímetro Micromeritics AutoPore IV $9500 \mathrm{~V} 1.09$.

\section{RESULTADOS E DISCUSSÃO}

A Fig. 1 ilustra os resultados da análise granulométrica da composição em estudo.

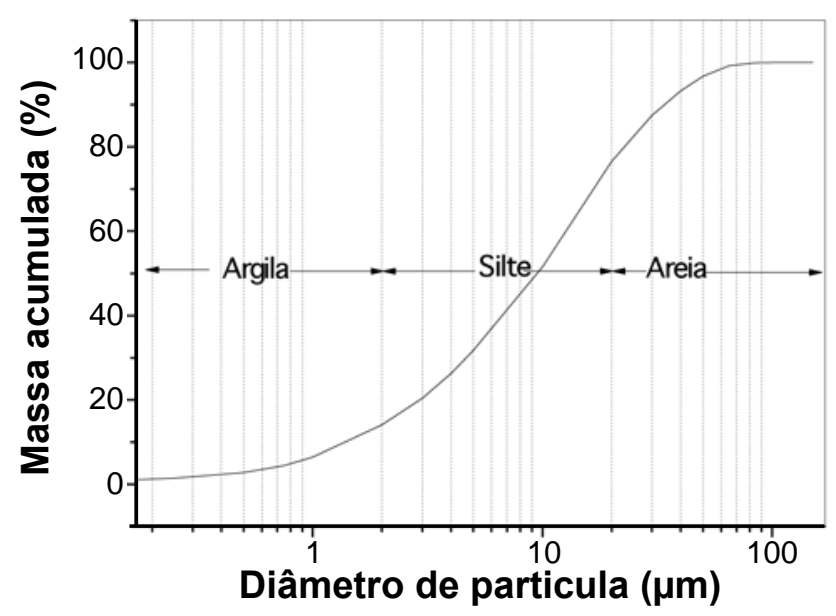

Figura 1: Distribuição granulométrica da massa cerâmica. [Figure 1: Particle size distribution of ceramic mass.]

A distribuição do tamanho de partículas apresenta diâmetro médio das partículas em $\sim 13,9 \mu \mathrm{m}$; cerca de $14,1 \%$ da massa acumulada é menor que $2 \mu \mathrm{m}$, corresponde à fração argila, 76,6\% corresponde ao teor de silte, e 9,4\% está relacionado ao teor de areia. Embora esta distribuição granulométrica seja bastante larga, verifica-se um alto teor de partículas com tamanhos na faixa de 2 a $10 \mu \mathrm{m}$, bem como uma fração considerável de partículas abaixo de $2 \mu \mathrm{m}$. É de se esperar com esta distribuição uma boa compactação entre partículas finas e grossas após conformação, de maneira que se tenham poros submicrométricos e um elevado grau de sinterização após queima.

A Tabela I ilustra os resultados das composições químicas da massa cerâmica.

Verifica-se que a composição em estudo é constituída basicamente de sílica (> 64\%) devido principalmente à presença de quartzo e alumina $(\sim 28 \%)$, proveniente do
Tabela II - Composição química da massa cerâmica. [Table II-Chemical composition of ceramic mass.]

\begin{tabular}{cc}
\hline Óxidos $(\%$ em peso $)$ & Massa Cerâmica \\
\hline Óxido de Silício $\left(\mathrm{SiO}_{2}\right)$ & 65,12 \\
Óxido de Alumínio $\left(\mathrm{Al}_{2} \mathrm{O}_{3}\right)$ & 28,75 \\
Óxido de Ferro $\left(\mathrm{Fe}_{2} \mathrm{O}_{3}\right)$ & 1,93 \\
Óxido de Cálcio $(\mathrm{CaO})$ & 1,31 \\
Óxido de Magnésio $(\mathrm{MgO})$ & 1,35 \\
Óxido de Potássio $\left(\mathrm{K}_{2} \mathrm{O}\right)$ & 0,60 \\
Óxido de Titânio $\left(\mathrm{TiO}_{2}\right)$ & 0,58 \\
Outros & 0,34 \\
\hline
\end{tabular}

caulim e da bentonita. Espera-se com esta composição obter após queima uma fase mulita e também um excesso de quartzo. A massa cerâmica contém um teor de óxido de ferro menor que $2 \%$, confirmando a hipótese de matériaprima que favorece uma queima com aparência clara. Baixos teores de $\mathrm{CaO}$ e $\mathrm{MgO}$ são importantes, pois estes atuam como agentes fundentes. Esses óxidos em elevadas quantidades poderia interferir no processo de sinterização, favorecendo o surgimento de formação de fase liquida.

A Fig. 2 ilustra a curva da análise termogravimétrica da massa cerâmica.

Há três estágios de perda de massa. O primeiro entre 25 e $230{ }^{\circ} \mathrm{C}$, possivelmente relacionado à eliminação de água adsorvida e estrutural do material, outro estágio de 230 a $493{ }^{\circ} \mathrm{C}$, relacionado à perda de matéria orgânica e hidroxilas presentes na composição e, finalmente, o último estágio entre 493 e $720^{\circ} \mathrm{C}$, que ocorre em consequência da decomposição de carbonatos e hidróxidos. A perda de massa total apresentada pela composição foi de aproximadamente 13,0\%. Com está análise foi possível definir a curva de queima, como descrito anteriormente.

A Fig. 3 ilustra o resultado da difração de raios $X$ da massa cerâmica. $\mathrm{O}$ difratograma registra as fases esmectita, caulinita, quartzo e mica, caracterizadas por meio dos

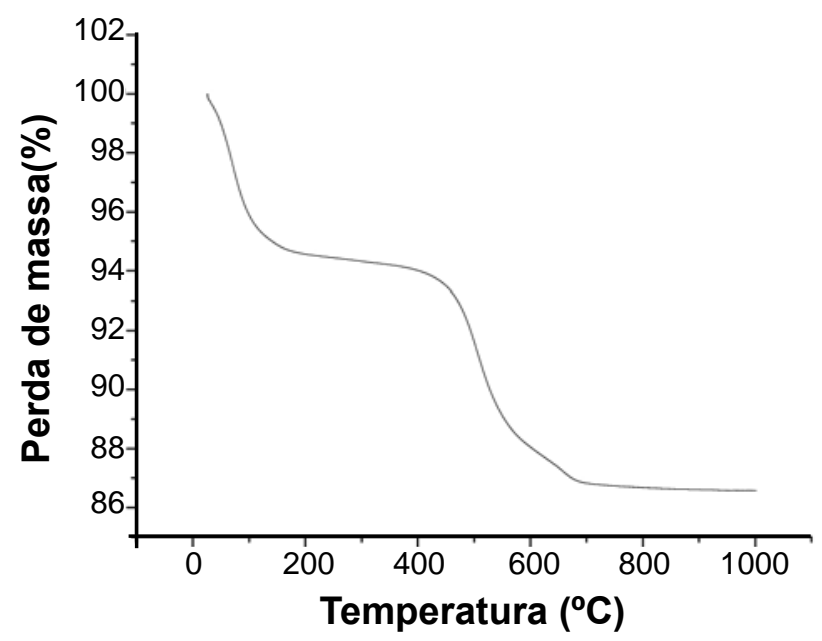

Figura 2: Curva de análise termogravimétrica da massa cerâmica. [Figure 2: Thermogravimetric curves of the ceramic mass.] 
arquivos JCPDS 29-1497, 29-1488, 46-1045 e 42-1339, respectivamente. Este resultado está de acordo com a composição da massa cerâmica obtida a partir da mistura de caulim, bentonita e quartzo.

Fig. 4 apresenta os resultados de difração de raios X das amostras sinterizadas.

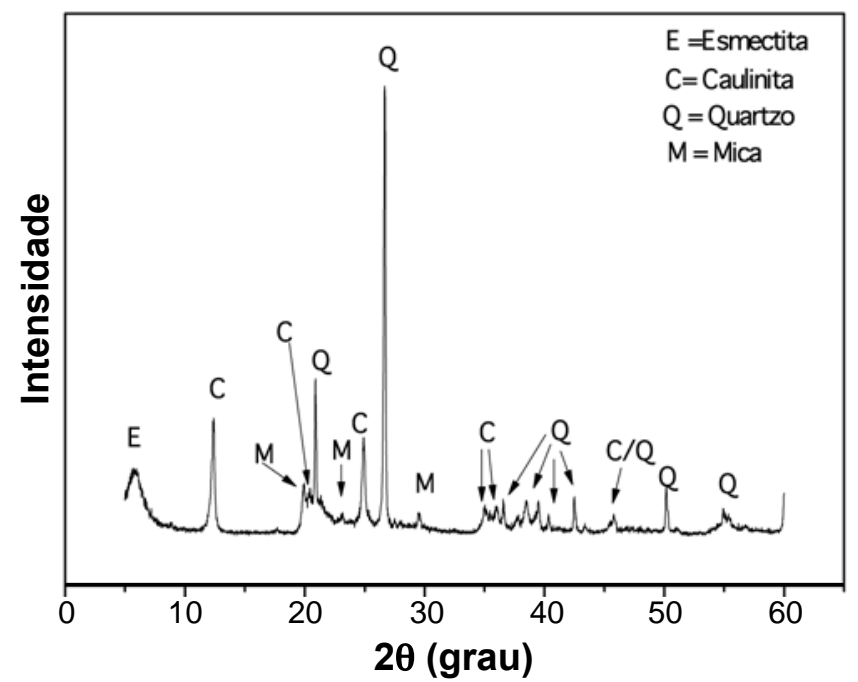

Figura 3: Difratograma de raios $\mathrm{X}$ da massa cerâmica. [Figure 3: X-ray diffraction pattern of the ceramic mass.]
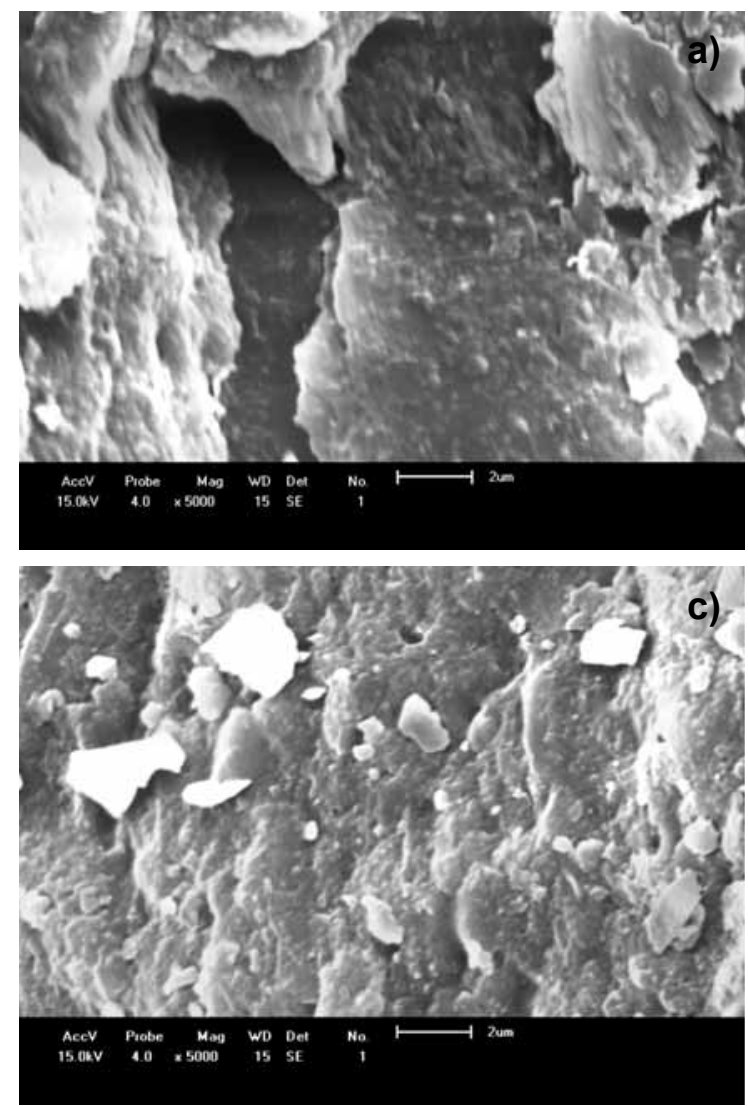

A $800{ }^{\circ} \mathrm{C}$ foi possível identificar a presença de mica e quartzo, caracterizados pelo arquivo JCPDS 42-1339 e 850794. A 900 e a $1000{ }^{\circ} \mathrm{C}$ predominou a presença de quartzo, caracterizado pelo arquivo JCPDS 85-0794. A $1100{ }^{\circ} \mathrm{C}$ surgiram novas fases, $\mathrm{o}$ aumento da temperatura favoreceu $\mathrm{o}$ surgimento da fase cristobalita, que é uma fase de transição

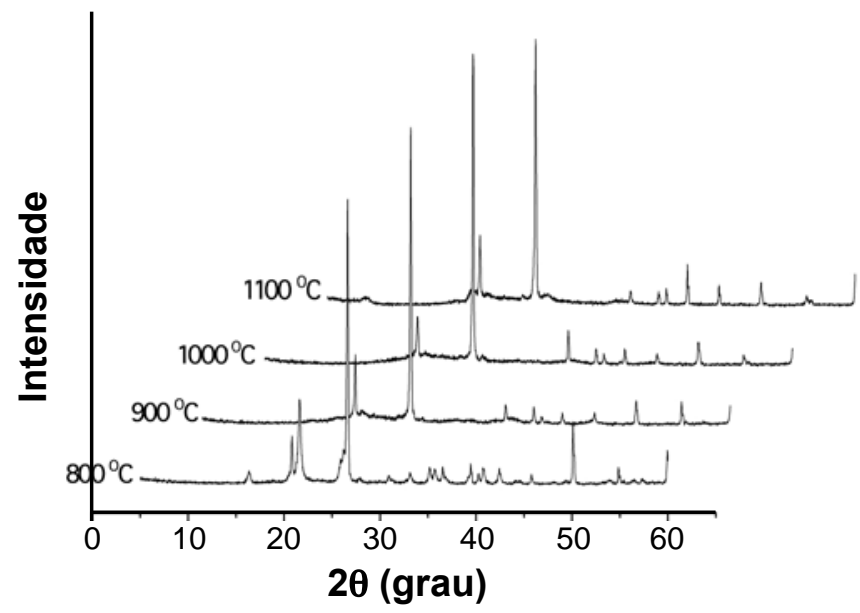

Figura 4: Difratogramas de raios $\mathrm{X}$ das amostras sinterizadas a 800 , 900,1000 e $1100^{\circ} \mathrm{C}$.

[Figure 4: X-ray diffraction patterns of the samples sintered at 800 , 900,1000 and $1100^{\circ} \mathrm{C}$.]
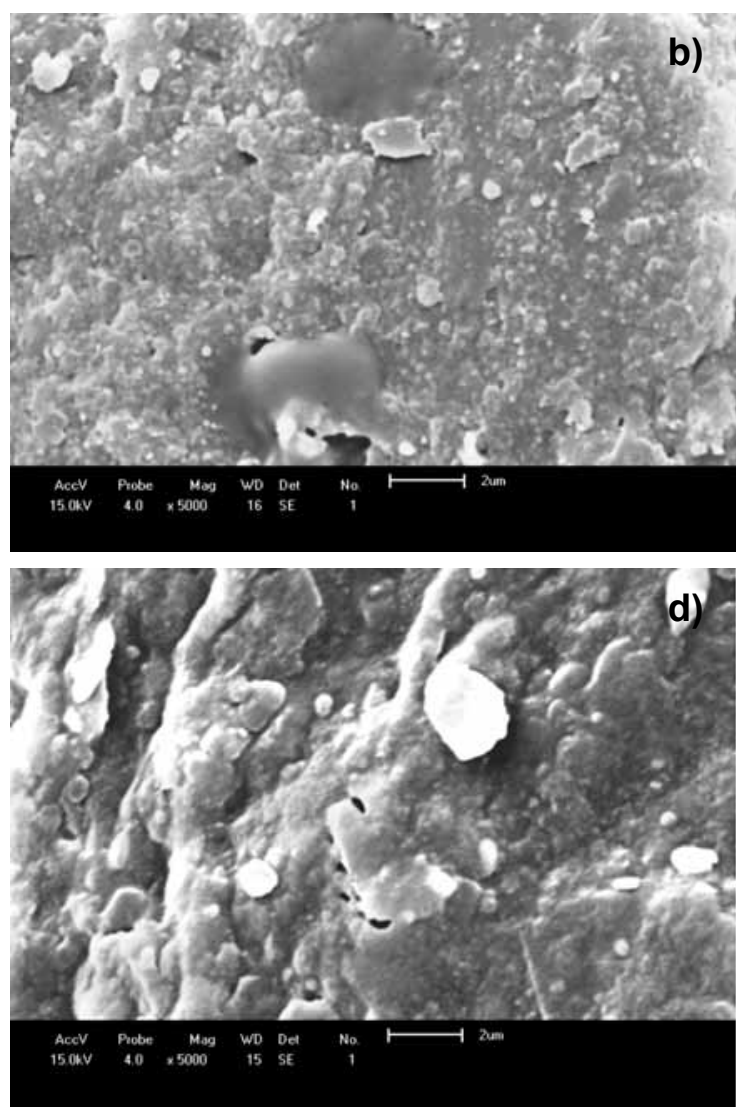

Figura 5: Micrografias obtidas por microscopia eletrônica de varredura das membranas cerâmicas sinterizadas a: (a) $800{ }^{\circ} \mathrm{C}$; (b) $900{ }^{\circ} \mathrm{C}$; (c) $1000^{\circ} \mathrm{C}$; (d) $1100^{\circ} \mathrm{C}$.

[Figure 5: SEM micrographs of ceramic membranes sintered at: (a) $800{ }^{\circ} \mathrm{C}$; (b) $900{ }^{\circ} \mathrm{C}$; (c) $1000^{\circ} \mathrm{C}$; (d) $1100^{\circ} \mathrm{C}$.] 
do quartzo, e picos característicos da nucleação da mulita, identificados pelas pelos arquivos JCPDS 89-3435 e 15-0776, respectivamente. Quando a massa cerâmica é aquecida em temperatura acima de $1000{ }^{\circ} \mathrm{C}$, tanto a caulinita (presente no caulim), como também a esmectita (presente na bentonita) se dissociam em mulita e sílica, pois a quantidade de $\mathrm{SiO}_{2}$ na caulinita e esmectita é maior do que na mulita $\left(3 \mathrm{Al}_{2} \mathrm{O}_{3} \cdot 2 \mathrm{SiO}_{2}\right)$. Em altas temperaturas, a sílica forma uma fase vítrea junto com as impurezas (óxidos de potássio, cálcio, magnésio e ferro) presentes nas argilas [13]. Entretanto, a mulita não foi encontrada nas membranas sinterizadas abaixo de $1000^{\circ} \mathrm{C}$. A presença de partículas grandes de quartzo na massa cerâmica diminui a cinética de formação de mulita [14]. Provavelmente este comportamento é responsável pela presença de quartzo e cristobalita na membrana sinterizada.

A Fig. 5 ilustra as micrografias das membranas sinterizadas a $800,900,1000$ e $1100{ }^{\circ} \mathrm{C}$.

Estas imagens foram obtidas para avaliar a microestrutura das membranas cerâmicas, bem como a distribuição e o tamanho médio de poros. As superfícies das membranas (Fig. 5) indicam que as distribuições dos poros não são uniformes. Não foi possível estimar com precisão o tamanho dos poros nas diferentes membranas, no entanto verifica-se uma diferença no aspecto superficial das micrografias, com as membranas sinterizadas em $1100{ }^{\circ} \mathrm{C}$, apresentando maior formação de fase líquida. Nesta temperatura ocorre uma sinterização com maior

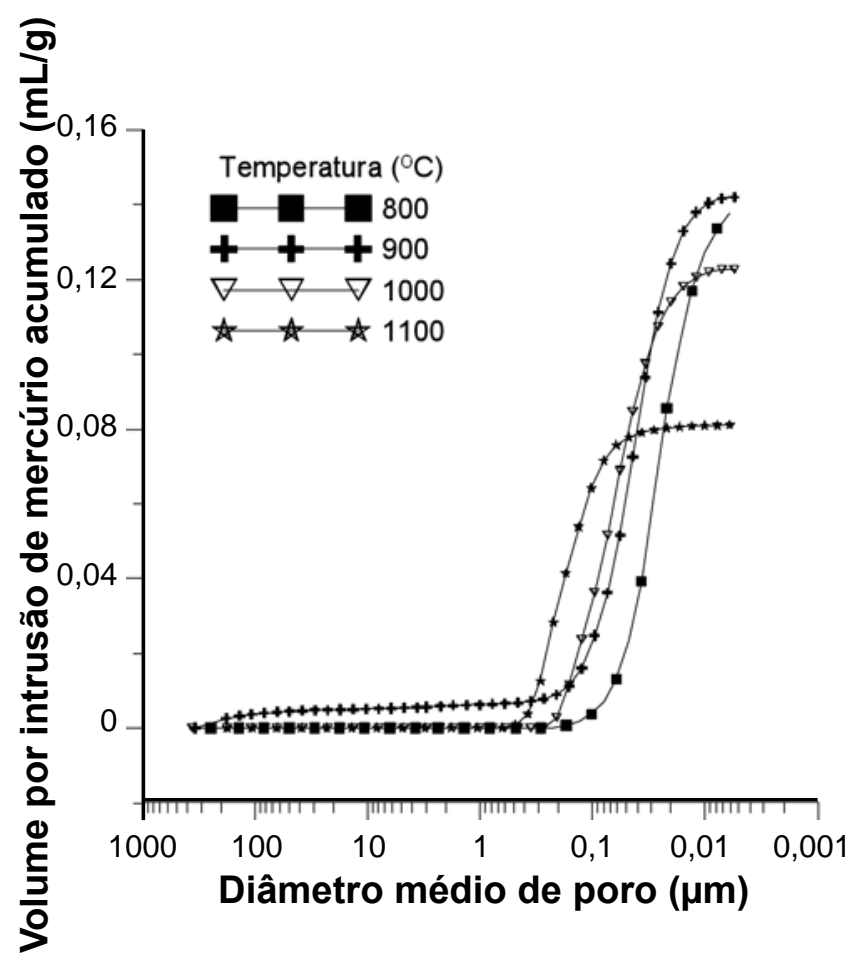

Figura 6: Diâmetro médio de poros em função do volume de intrusão de mercúrio acumulado nas membranas cerâmicas sinterizadas em diferentes temperaturas.

[Figure 6: Pore size distribution as a function of mercury intrusion volume for ceramic membranes sintered at different temperatures]. escoamento de fase liquida, favorecendo a diminuição da porosidade, com o fechamento dos poros pequenos em detrimento do aumento dos poros maiores.

A distribuição do diâmetro médio de poros em função do volume de intrusão acumulada de mercúrio das membranas tubulares sinterizadas nas temperaturas de $800,900,1000 \mathrm{e}$ $1100{ }^{\circ} \mathrm{C}$ está apresentada na Fig. 6 .

Os valores da porosidade e diâmetro médio dos poros estão apresentados na Tabela II. As membranas cerâmicas tubulares apresentaram a grande maioria de poros variando de 0,02 a $0,1 \mu \mathrm{m}$, o que classifica esta membrana na faixa de ultrafiltração.

Tabela II - Diâmetro médio dos poros e porosidade das membranas sinterizadas nas temperaturas de $800,900,1000$ e $1100{ }^{\circ} \mathrm{C} / 2 \mathrm{~h}$.

[Table II - Average pore diameter and porosity of the sintered ceramic membranes sintered at temperatures of 800,900 , 1000 and $1100^{\circ} \mathrm{C} / 2 \mathrm{hJ}$.

\begin{tabular}{ccc}
\hline $\begin{array}{c}\text { Temperatura } \\
\text { de sinterização } \\
\left({ }^{\circ} \mathrm{C}\right)\end{array}$ & $\begin{array}{c}\text { Diâmetro médio } \\
\text { dos poros } \\
(\mu \mathrm{m})\end{array}$ & $\begin{array}{c}\text { Porosidade } \\
(\%)\end{array}$ \\
\hline 800 & 0.021 & 25,82 \\
900 & 0.036 & 26,69 \\
1000 & 0.047 & 24,18 \\
1100 & 0.124 & 16,98 \\
\hline
\end{tabular}

De acordo os resultados obtidos na Fig. 6 e ilustrados na Tabela II, verifica-se que a elevação na temperatura de sinterização provocou aumento no diâmetro médio dos poros das membranas cerâmicas e uma diminuição da porosidade. A diminuição da porosidade ocorreu provavelmente porque a elevação da temperatura de sinterização provoca, além de crescimento de grãos, formação de fase líquida, gerando assim uma maior densificação. A formação de fase líquida favorece ao crescimento de grãos e coalescência dos poros [16]. Em relação ao aumento do diâmetro médio dos poros provavelmente ocorreu devido ao escoamento de formação da fase líquida, que levou ao preenchimento dos poros menores, conseqüentemente aumentando os poros maiores.

\section{CONCLUSÕES}

Membranas cerâmicas tubulares foram produzidas com sucesso, utilizando matérias-primas naturais. Os resultados de caracterização indicaram que a massa cerâmica obtida a partir de bentonita, caulim e quartzo podem ser utilizadas como matéria-prima promissora para obtenção de membranas cerâmicas na escala de ultrafiltração, com tamanho de poros na faixa $0,02-0,1 \mu \mathrm{m}$. Verificou-se que o aumento na temperatura de sinterização teve forte influência na porosidade bem como no tamanho de poros. 


\section{AGRADECIMENTOS}

Ao CNPq pela concessão da bolsa, e ao Departamento de Engenharia de Materiais/CCT/UFCG.

\section{REFERÊNCIAS}

[1] M. R. Weir, E. Rutinduka, C. Detellier, C. Y. Feng, Q. Wang, T. Matsuura, R. Le Van Mao, Fabrication, characterization and preliminary testing of all-inorganic ultrafiltration membranes composed entirely of a naturally occurring sepiolite clay mineral, J. Membrane Sci. 182. (2001) 41-50.

[2] Y. Dong, S. Chen, X. Zhang, J. Yang, X. Liu, G. Meng, Fabrication and characterization of low cost tubular mineral-based ceramic membranes for micro-filtration from natural zeolite, J. Membrane Sci. 281 (2006) 592-599.

[3] B. C. Perez, "As rochas e os minerais industriais como elemento de desenvolvimento sustentável", Série Rochas e Minerais Industriais, CETEM/MCT, Rio de Janeiro, RJ (2001) 37.

[4] M. P. B. Oliveira, P. Normando, Potencialidades de um caulim calcinado como material de substituição parcial do cimento portland em argamassas, Ver. Bras. Eng. Agr. Amb. 10 (2006) 490-496.

[5] R. R. Menezes, M. M. Ávila Jr., L. N. L. Santana, G. A. Neves, H. C. Ferreira, Comportamento de expansão de argilas bentoniticas organofilicas do estado da Paraíba, Cerâmica 54 (2008) 152-159

[6] Lenntech, "Water treatment and air purification", disponível em $\quad<$ http://www.lenntech.com/espanol/ tecnologia-de-membrana.htm>, acesso em 25/08/2008.

[7] R. Soria, Catalysis Today 25 (1995) 285-290.

[8] F. Quemeneur, P. Jaquen. Proc. $2^{\text {nd }}$ Int. Conf. Inorg. Membranes, Montpellier, France, (1991) 585.

[9] E. P. Santos, L. R. B. Santos, C. V. Santilli, S. H. Pulcinelli, Anais $12^{\circ}$ Cong. Bras. Ci. Eng. Mater. (CBECIMAT), Águas de Lindóia, SP (1996).

[10] R. C. O. Lima, H. L. Lira, G. A. Neves, M. C. Silva, C. D. Silva, Aproveitamento do resíduo de serragem de granito para fabricação de membranas cerâmicas de baixo custo, Rev. Elet. Mater. Proc. 6 (2011)163-169.

[11] M. Mulder, "Basic Principles of Membrane Technology", $1^{\text {st }}$ Ed., Kluwer Acad. Publ., Holanda (1991) 75.

[12] F. A. Silva, H. L. Lira, Preparação e caracterização de membranas cerâmicas de cordierita, Cerâmica 52 (2006) 276-282.

[13] J. Li, H. Lin, J. Li, J. Wu, Effects of different potassium salts on the formation of mullite as the only crystal phase in kaolinite, J. Eur. Ceram. Soc. 29 (2009) 2929-2936.

[14] R. R. Menezes, F. F. Farias, M. F. Oliveira, L. N. L. Santana, G. A. Neves, H. L. Lira, H. C. Ferreira, Kaolin processing waste applied in the manufacturing of ceramic tiles and mullite bodies, Waste Management \& Res. 26 (2008) 1-9.

[15] F. A. Silva, "Desenvolvimento de Membranas Cerâmicas Tubulares a Partir de Matérias-Primas Regionais para Processo de Microfiltração", Tese Dr., Universidade Federal de Campina Grande, PB (2009).

[16] R. M. German, "Sintering Theory and Pratice", Wiley Intersci., New York, EUA (1996) 109.

(Rec. 09/02/2012, Rev. 19/04/2012, Ac. 06/05/2012) 